\title{
Синтез и применение магнитных молекулярно импринтированных тетрациклином полимерных наночастиц в пьезоэлектрическом сенсоре
}

\author{
(c) 2021 Бизина Е.В., Фарафонова О.В., Тарасова Н.В., Ермолаева Т.Н. \\ Липеикий государственный технический университет, Липецฺк
}

Поступила в редакцию 1.02.2021 г.

DOI: $10.17308 /$ sorpchrom.2021.21/3352

Цель работы состояла в синтезе методом «core-shell by grafting» магнитных молекулярно-импринтированных тетрациклином полимерных наночастиц $\left(\mathrm{Fe}_{3} \mathrm{O}_{4} @\right.$ ПМО) и оценке возможности их применения в качестве распознающих компонентов пьезоэлектрического сенсора.

В ходе исследования были установлены условия синтеза магнитных частиц полимеров с молекулярными отпечатками тетрациклина методом «ядро-оболочка». Полимеры с молекулярными отпечатками (ПМО), синтезируемые методом «ядро-оболочка» («core-shell» или «core-shell by grafting») уже положительно зарекомендовали себя как селективные сорбенты для концентрирования и разделения различных органических соединений. При этом, во-первых, достигается сферическая форма ядра и повышается степень дисперсности синтезируемых частиц $\mathrm{Fe}_{3} \mathrm{O}_{4} @$ ПМО, имеющих однородную морфологию поверхности, а во-вторых, молекулярные отпечатки концентрируются в довольно тонком слое, что ускоряет повторное связывание с шаблоном. Получение магнитных ядер осуществляли модифицированным методом соосаждения, далее проводили гидрофобизацию их поверхности олеиновой кислотой для облегчения закрепления полимерного слоя и затем синтезировали молекулярно-импринтированную полимерную «оболочку» методом свободной радикальной полимеризации с применением метакриловой кислоты и этиленгликольдиметакрилата.

Методом изучения спектра мутности установлены средние радиусы магнитных ядер $\mathrm{Fe}_{3} \mathrm{O}_{4}$

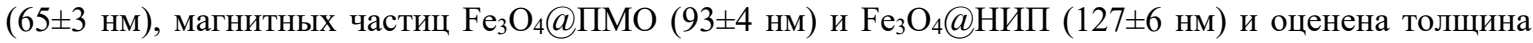

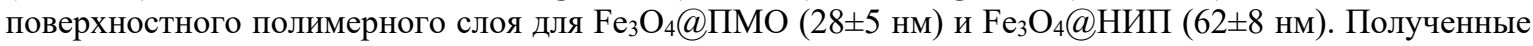
результаты коррелируют с размерами наночастиц, установленными методом АСМ. Изучены условия формирования распознающего слоя на основе частиц $\mathrm{Fe}_{3} \mathrm{O}_{4} @$ ПМО на поверхности золотого электрода пьезоэлектрического сенсора под действием магнитного поля, создаваемого неодимовым магнитом. Метод пьезокварцевого микровзвешивания оценена поверхностная концентрация молекулярных отпечатков и устойчивость распознающего слоя на основе магнитных частиц $\mathrm{Fe}_{3} \mathrm{O}_{4} @$ @МО тетрациклина. Установлены метрологические характеристики пьезоэлектрического сенсора для определения тетрациклина: получено уравнение градуировочной функции, определен диапазон определяемых содержа-

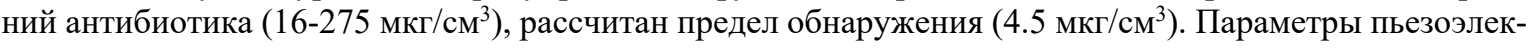
трического сенсора на базе магнитных частиц $\mathrm{Fe}_{3} \mathrm{O}_{4} @$ @МО свидетельствуют о возможности его применения для выявления и определения тетрациклина в жидких средах.

Ключевые слова: тетрациклин, полимеры с молекулярными отпечатками, метод «ядро-оболочка», поверхностный импринтинг, распознающий слой пьезоэлектрического сенсора.

\section{Введение}

В настоящее время существенный интерес исследователей вызывает поиск новых магнитных сорбентов, позволяющих значительно упростить процессы выделения и разделения компонентов пробы в ходе пробоподготовки [1-4]. Наиболее часто магнитные сорбенты получают способом «ядро-оболочка» путем нековалентного или ковалентного закрепления 
на поверхности ядер на базе оксидов железа неорганических [5-7] или органических соединений [8-10], а также синтезом углеродных или полимерных нанокомпозитов, допированных магнитными наночастицами [11-13].

Достаточно подробно описаны методы синтеза магнитных ядер $\mathrm{Fe}_{3} \mathrm{O}_{4}[14,15]$. На размер магнитных наночастиц существенное влияние оказывают условия синтеза. Повысить их однородность можно проведением нагревания в микроволновом поле [16]. Формирование на поверхности магнитных ядер полимерных покрытий на основе синтетических или природных полимеров обеспечивает увеличение сорбционной способности. Для функционализации поверхности наночастиц оксидов железа используют как синтетические, так и природные полимеры [17]. Устойчивость структур магнитных сорбентов существенно возрастает при формировании многослойных оболочек.

Полимеры с молекулярными отпечатками (ПМО), синтезируемые методом «ядро-оболочка» («core-shell» или «coreshell by grafting») уже положительно зарекомендовали себя как селективные сорбенты для концентрирования и разделения различных органических соединений. При этом, во-первых, достигается сферическая форма ядра и повышается степень дисперсности синтезируемых частиц $\mathrm{Fe}_{3} \mathrm{O}_{4} @$ @МО, имеющих однородную морфологию поверхности, а во-вторых, молекулярные отпечатки концентрируются в довольно тонком слое, что ускоряет повторное связывание с шаблоном $[18,19]$. Полученные описанными способами сорбенты, как правило, применяются для выделения и концентрирования методом магнитной твердофазной экстракции широкого перечня лекарственных веществ [20-22], однако их применение в сенсорике ограничено в основном электрохимическими сенсорами [23]. В пьезоэлектрических сенсорах они используются относительно редко, несмотря на то, что магнитные «core-shell» наносферы $\mathrm{Fe}_{3} \mathrm{O}_{4} @$ @МО на основе метода поверхностного импринтинга (coreshell by grafting) могут существенно pacширить аналитические возможности пьезоэлектрических сенсоров, упростить процедуру формирования распознающего слоя и повысить его устойчивость.

Цель работы состояла в синтезе методом «core-shell by grafting» магнитных молекулярно-импринтированных тетрациклином полимерных наночастиц $\left(\mathrm{Fe}_{3} \mathrm{O}_{4} @\right.$ ПМО) и оценке возможности их применения в качестве распознающих компонентов пьезоэлектрического сенcopa.

\section{Экспериментальная часть}

Реактивы и рабочие растворы. $\mathrm{FeSO}_{4} \cdot 7 \mathrm{H}_{2} \mathrm{O}$, ч.д.а.; $\mathrm{Fe}_{2}\left(\mathrm{SO}_{4}\right)_{3} \cdot 9 \mathrm{H}_{2} \mathrm{O}$, ч.д.а. («НеваРеактив», Россия); соляная кислота ч.д.а. («Химреативснаб», Россия); аммиак (25\%) («Минимед», Россия); олеиновая кислота («НеваРеактив», Россия); уксусная кислота («База №1 химреактивов», Россия); гидроксид натрия («НеваРеактив», Россия); ацетонитрил («Вектон», Россия); метактиловая кислота, МАA («Вектон», Россия); этиловый спирт, х.ч. (ОАО «Метафракс», Россия); этиленгликольдиметокрилат, EGDMA («Sigma-Aldrich», Великобритания); инициатор полимеризации 2,2-изо-бис-изобутиролнитрил, AIBN («Лабтех», Россия); как ПАВ-стабилизатор повинилпирролидон ПВП («Aplichem Gmbh», Германия); толуол («Вектон», Россия); тетрациклина гидрохлорид («Алмабион», Россия) (рис. 1).

Аппаратура и методика эксперимента. Спектры поглощения и оптические плотности растворов регистрировали на спектрофотометре UV-1800 (Shimadzu, Япония), значения $\mathrm{pH}$ контролировали на $\mathrm{pH}-$ метре-иономере «Эксперт 001» («Эконикс-Эксперт», Россия). Гомогенизацию наночастиц проводили путем ультразвуковой обработки (ультразвуковая ванна 
<smiles>CN(C)C1CC2C(=C(O)[C@H]3C(=O)c4c(O)cccc4[C@@]3(C)O)C(=O)C(C(N)=O)=C(O)C2CC1Cl</smiles>

Рис. 1. Структурная формула тетрациклина гидрохлорида

Fig. 1. Structural formula of tetracycline hydrochloride

ПСБ-2835-03, «ПСБ-Галс», Россия) с частотой 40 кГц. Размер наночастиц оценивали методом спектра мутности (турбидиметрический метод) и методом атомной силовой микроскопии (сканирующий зондовый микроскоп «Solver P47-PRO» (ЗАО «Нанотехнология-МДТ», Зеленоград, Россия). Турбидиметрические измерения проводили с использованием коллоидных растворов магнитных наночастиц с концентрацией 0.01 и $0.05 \mathrm{M \Gamma} / \mathrm{cm}^{3}$, определяя оптическую плотность мутных растворов в зависимости от длины волны падающего света. По тангенсу угла наклона зависимости $\ln \mathrm{A}=\mathrm{f}(\ln \lambda)$ находили величину углового коэффициента n, a затем с помощью градуировочной кривой Геллера, описывающей зависимость показателя степени $\mathrm{n}$ от радиуса частиц $r$, рассчитывали средний радиус частиц исследуемой дисперсной системы.

Синтез магнитных частиц

$\mathrm{Fe}_{3} \mathrm{O}_{4} @$ ПМО. Подготовка магнитных ПМО наночастиц включала три последовательных этапа (рис. 2):

- синтез наночастиц $\mathrm{Fe}_{3} \mathrm{O}_{4}$ по модифицированному методу соосаждения;
- модификацию (поверхностную гидрофобизацию) $\mathrm{Fe}_{3} \mathrm{O}_{4}$ с помощью олеиновой кислоты с целью снижения способности к агрегированию и облегчения закрепления полимерного слоя на поверхностности магнитного ядра;

- синтез молекулярно-импринтированного полимерного слоя («оболочки») на поверхности магнитных наночастиц методом свободной радикальной полимеризации на основе метакриловой кислоты и этиленгликольдиметокрилата, ранее положительно зарекомендовавших себя при синтезе ПМО [24-26]. В качестве инициатора полимеризации применяли 2,2-изобис-изобутиролнитрил.

Для синтеза ядер $\mathrm{Fe}_{3} \mathrm{O}_{4}$ по модифицированному методу соосаждения Массарта 0.02 моль $\mathrm{FeSO}_{4} \cdot 7 \mathrm{H}_{2} \mathrm{O}$ и 0.03 моль $\mathrm{Fe}_{2}\left(\mathrm{SO}_{4}\right)_{3} \cdot 9 \mathrm{H}_{2} \mathrm{O}$ растворяли в $100 \mathrm{~cm}^{3}$ дистиллированной воды, затем в раствор вводили $2.0 \mathrm{~cm}^{3}$ олеиновой кислоты, обрабатывали ультразвуком в течение 20 мин. Далее к раствору по каплям добавляли $15 \mathrm{~cm}^{3} 25 \%$ раствор аммиака и нагревали до температуры $60^{\circ} \mathrm{C}$.

Через 30 мин вводили по каплям еще одну порцию олеиновой кислоты $\left(2.0 \mathrm{~cm}^{3}\right)$

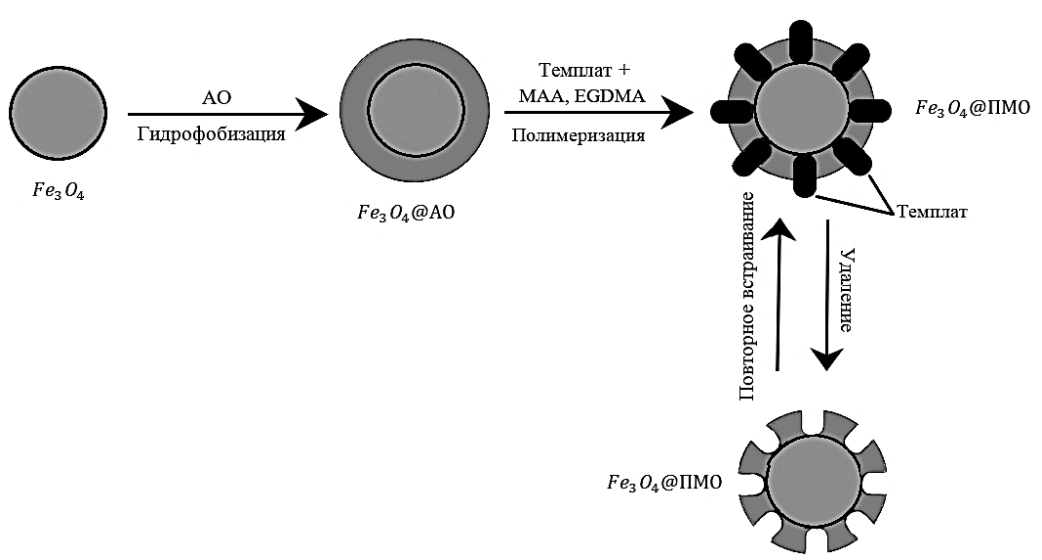

Рис. 2. Синтез магнитных импринтированных ПМО наночастиц $\mathrm{Fe}_{3} \mathrm{O}_{4}$ Fig. 2. Synthesis of magnetic imprinted $\mathrm{Fe}_{3} \mathrm{O}_{4}$ MIP nanoparticles 
для поверхностной гидрофобизации частиц и выдерживали в течение 1 ч при температуре $80^{\circ} \mathrm{C}$ при постоянном перемешивании. После окончания синтеза полученный магнитный осадок отделяли, последовательно промывали водой и этанолом и высушивали при комнатной температуре в течение 120 ч.

Для получения «оболочки» предварительно суспендировали в $1 \mathrm{~cm}^{3}$ толуола магнитные наночастицы $\mathrm{Fe}_{3} \mathrm{O}_{4}$ (0.215 ммоль), 0.1 ммоль шаблона (тетрациклина гидрохлорид) и метакриловую кислоту (0.4 ммоль) и оставляли при температуре $4^{\circ} \mathrm{C}$ на 1 ч. Далее в полученную систему вводили кросс-реагент этиленгликольдиметакрилат (2.5 ммоль) и инициатор полимеризации (0.075 ммоль) и гомогенизировали путем ультразвуковой обработке в течение 5 мин. Затем к полученному раствору по каплям добавляли $6 \mathrm{~cm}^{3}$ водного раствора ПВП $\left(25 \mathrm{Mг} / \mathrm{cm}^{3}\right)$ и проводили полимеризацию при $60{ }^{\circ} \mathrm{C}$ при постоянном перемешивании со скоростью 30 об/мин в течение 4 ч $[21,22]$. По аналогичной методике, но без добавления тетрациклина в процессе синтеза, были получены неимпринтированные магнитные частицы - $\mathrm{Fe}_{3} \mathrm{O}_{4} @$ НИП.

Изучение условий формирования распознающего слоя сенсора на основе

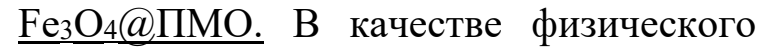
преобразователя сенсора использовали пьезокварцевые резонаторы АТ-среза с собственной частотой колебаний 10 МГц \pm 1 Гц с золотыми электродами (диаметр 5 мм) (ЗАО « ЭТНА», Россия). Аналитический сигнал сенсора $\left(\Delta \mathrm{F}_{\text {ан, }}\right.$ Гц $)$ реги- стрировали в статическом режиме на приборе «CРNA-330» (3АО «ЭТНА», Россия). Перед формированием распознающего слоя поверхность электрода резонатора очищали $1 \mathrm{M}$ раствором соляной кислоты, ацетоном и этанолом. Сенсор располагали над неодимовым магнитом (рис. 3), наносили 3 мм $^{3}$ суспензии $\mathrm{Fe}_{3} \mathrm{O}_{4} @$ ПМО, сушили в потоке теплого воздуха в течение 1 ч. Промывали сенсор $200 \mathrm{mм}^{3}$ дистиллированной воды и сушили до постоянной массы.

Характеристика распознающего слоя на основе наночастиц ПМО осуществлялась методом пьезокварцевого микровзвешивания аналогично описанной в работах [24-26]. В качестве аналитического сигнала использовали изменение частоты колебаний после высушивания сенсора до постоянной массы на воздухе до и после формирования пленки на основе наночастиц ПМО, встраивания в молекулярные отпечатки и удаления молекул тетрациклина.

Maccy $\mathrm{Fe}_{3} \mathrm{O}_{4} @$ ПМО-покрытия сенсора $(\Delta$ тпмо, мкг) рассчитывали по уравнению Зауэрбрея [27]. Для исключения влияния неспецифической сорбции аналитический сигнал измеряли относительно сенсора сравнения на основе НИП.

Массу (мкг) удаленного и повторно встроенного тетрациклина рассчитывали по уравнениям (1) и (2) соответственно:

$$
\begin{gathered}
\Delta m_{B C}=\frac{S \cdot\left|F_{\text {ПМО }}-F_{1}\right|}{2,3 \cdot 10^{6} \cdot F_{\text {ПМО }}^{2}} \\
\Delta m_{\text {ПВС }}=\frac{\mathrm{S} \cdot \Delta \mathrm{F}_{\text {ан }}}{2,3 \cdot 10^{6} \cdot F_{1}^{2}},
\end{gathered}
$$

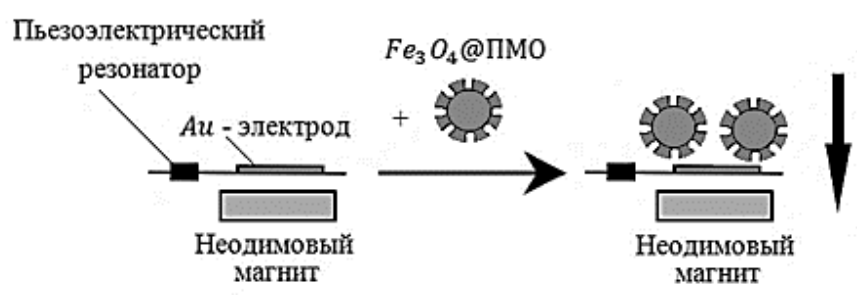

Рис. 3. Иммобилизация частиц $\mathrm{Fe}_{3} \mathrm{O}_{4} @$ ПМО на поверхности пьезоэлектрического сенсора при помощи неодимового магнита

Fig. 3. Immobilization of $\mathrm{Fe}_{3} \mathrm{O}_{4} @ \mathrm{MIP}$ particles on the surface of a piezoelectric sensor using a neodymium magnet 
где $\mathrm{F}_{1}$ - частота после удаления тетрацик-

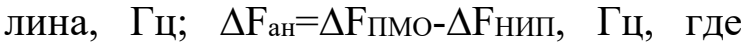
$\Delta \mathrm{F}_{\text {пмо и }} \Delta \mathrm{F}_{\text {нип }}=\mathrm{F}_{1}-\mathrm{F}_{2}-$ изменение частоты колебаний сенсора с покрытием из ПМО или НИП, F1, F 2 - частота колебаний сенсора до и после погружения в раствор тетрациклина соответственно.

Концентрацию поверхностных отпечатков тетрациклина (ммоль $/ \mathrm{cm}^{2}$ ) на поверхности иммобилизованных магнитных частиц определяли методом пьезокварцевого микровзвешивания после удаления и повторного встраивания молекул темплата по формуле (3):

$$
\mathrm{R}=\Delta \mathrm{mBC} /(\mathrm{S} \cdot \mathrm{MTц}) \text {, }
$$

где $\Delta \mathrm{mBc}$ - масса удаленного при вымывании тетрациклина, включенная в полимерный слой и участвующая в образовании поверхностных молекулярных отпечатков, мкг; Мтц - молекулярная масса тетрациклина.

\section{Обсуждение результатов}

Синтез сорбентов Fе3 $\mathrm{O}_{4} @$ ПМО методом core-shell by grafting. Весьма перспективно применение для концентрирования и определения тетрациклина, остаточные количества которого могут присутствовать в объектах окружающей среды или пищевых продуктах, магнитных наночастиц $\mathrm{Fe}_{3} \mathrm{O}_{4} @$ @МО, на поверхности которых присутствуют трехмерные отпечатки, способные к специфическим комплементарным взаимодействиям с целевыми молекулами темплата. Это обеспечивает селективное связывание тетрациклина с ПМО в присутствии других родственных соединений.

Методом турбидиметрии, базирующемся на измерении интенсивности света, прошедшего через дисперсную систему, оценены размеры магнитного ядра, молекулярно импринтированных ( $\left.\mathrm{Fe}_{3} \mathrm{O}_{4} @ \Pi \mathrm{MO}\right)$ и неимпринтировапнных ( $\mathrm{Fe}_{3} \mathrm{O}_{4} @$ @ИП) магнитных сферических наночастиц. Было установлено, что средний радиус магнитных ядер $\mathrm{Fe}_{3} \mathrm{O}_{4}$ составляет $65 \pm 3$ нм, магнитных частиц Fe $3 \mathrm{O}_{4} @ \Pi$ $127 \pm 6$ нм. Таким образом, толщина поверхностного полимерного слоя для

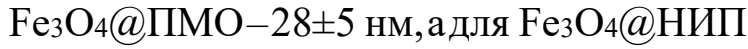
- $62 \pm 8$ нм. Увеличение толщины полимерного слоя неимпринтированных частиц может быть объяснено влиянием молекул темплата на процессы полимеризации. Полученные результаты коррелируют с данными АCM (рис. 4 a, б) $82 \pm 16$ нм для $\mathrm{Fe}_{3} \mathrm{O}_{4}, \quad 111 \pm 23$ нм для

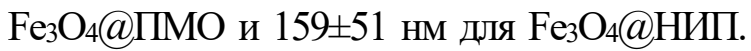
Распределение частиц по радиусам иллюстрирует рис. 4 в, г.

Применение частиц $\mathrm{Fe}_{3} \mathrm{O}_{4} @$ @МО в пьезоэлектрических сенсорах.

Изучены условия формирования распознающего слоя на основе частиц $\mathrm{Fe}_{3} \mathrm{O}_{4} @$ ПМО на поверхности золотого электрода сенсора под действием магнитного поля, создаваемого неодимовым магнитом. Изучено влияние объема наносимой на поверхность пьезоэлектрического сенсора суспензии $\mathrm{Fe}_{3} \mathrm{O}_{4} @$ ПМО на воспроизводимость результатов изменения массы распознающего слоя (табл. 1).

Как показывают экспериментальные данные максимальная воспроизводимость аналитического сигнала наблюдается при применении 3 мм $^{3}$ суспензии $\mathrm{Fe}_{3} \mathrm{O}_{4} @ \Pi M O$.

На эффективность сорбции молекул темплата наночастицами $\mathrm{Fe}_{3} \mathrm{O}_{4} @ \Pi M O$

Таблица 1. Влияние объема суспензии магнитных наночастиц на воспроизводимость сигнала сенсора $(\mathrm{P}=0.95, \mathrm{n}=3)$

Table 1. Effect of the volume of a suspension of magnetic nanoparticles on the reproducibility of the sensor signal $(\mathrm{P}=0.95, \mathrm{n}=3)$

\begin{tabular}{|c|c|c|}
\hline $\mathrm{V}_{\text {суспензии }}$, мм $^{3}$ & $\mathrm{~m}_{\text {покрытия, }}$ мкг & $\mathrm{s}_{\mathrm{r}}$ \\
\hline 1 & $1.4 \pm 0.9$ & 0.3 \\
\hline 2 & $3.4 \pm 1.3$ & 0.2 \\
\hline 3 & $6.1 \pm 1.1$ & 0.1 \\
\hline 4 & $12.7 \pm 7.7$ & 0.3 \\
\hline
\end{tabular}



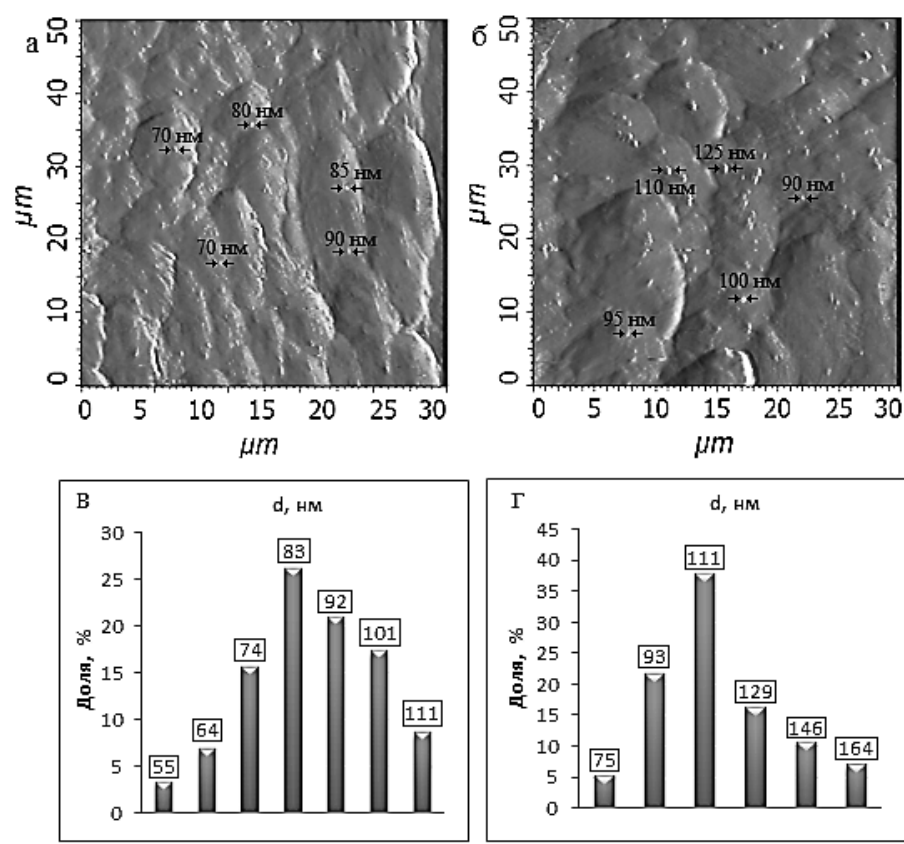

Рис. 4. АСМ-изображения магнитных частиц: (а) $\mathrm{Fe}_{3} \mathrm{O}_{4}$, (б) $\mathrm{Fe}_{3} \mathrm{O}_{4} @$ @МО и диаграммы распределения частиц по радиусам: (в) $\mathrm{Fe}_{3} \mathrm{O}_{4}$, (г) $\mathrm{Fe}_{3} \mathrm{O}_{4} @$ @МО

Fig. 4. AFM images of magnetic particles: (a) $\mathrm{Fe}_{3} \mathrm{O}_{4}$, (b) $\mathrm{Fe}_{3} \mathrm{O}_{4} @$ MIP and particle radii distribution diagrams: (c) $\mathrm{Fe}_{3} \mathrm{O}_{4}$, (d) $\mathrm{Fe}_{3} \mathrm{O}_{4} @$ MIP

существенное влияние оказывает выбор регенерирующего раствора, позволяющего максимально полно извлекать тетрациклин из молекулярных отпечатков без разрушения структуры полимерного слоя. Была оценена регенерирующая способность растворов уксусной кислоты и этанола в дистиллированной воде (1), раствора ацетонитрила и этанола (2) и дистиллированной воды (3). При использовании дистиллированной воды темплат извлекается за 1-2 мин, но затем наблюдается набухание полимерного слоя. Извлечение тетрациклина раствором ацетонитрила и этанола, взятых в объемном соотношении 1:2, приводит к разрушению структуры молекулярных отпечатков даже при однократном применении. И применение в качестве регенерирующего раствора уксусной кислоты и этанола в дистиллированной воде, взятых в объемных соотношениях 1:6:100, в течение 10 мин приводит к полному удалению темплата (рис. 5а). Для последующего использования слоя $\mathrm{Fe}_{3} \mathrm{O}_{4} @$ ПМО для сорбции тетрациклина необходимо установить продолжительность повторного встраивания молекул темплата в молекулярные отпечатки, которое, исходя из экспериментальных данных, составляет 6 мин (рис. 5 б).

Было отмечено, что масса тетрациклина, включенного в слой ПМО при синтезе наночастиц $\mathrm{Fe}_{3} \mathrm{O}_{4} @$ ПМО (m темплата, мкг), существенно превышает аналогичную характеристику, полученную при повторном встраивании, что может быть объяснено частичным разрушением полимерной структуры, прилегающей к отпечатку при первичной регенерации. Однако в результате последующих процедур вымывания - встраивания тетрациклина в молекулярные отпечатки, значения $\Delta \mathrm{mBC}_{1}$ и $\Delta \mathrm{mBC}_{2}$, а также $\mathrm{R}_{1}$ и $\mathrm{R}_{2}$ практически совпадают, что свидетельствует о формировании на поверхности $\mathrm{Fe}_{3} \mathrm{O}_{4} @$ ПМО постоянного количества доступных отпечатков (табл. 2).

Установлены метрологические характеристики пьезоэлектрических сенсоров для определения тетрациклина с распознающим слоем на основе $\mathrm{Fe}_{3} \mathrm{O}_{4} @ \Pi$ ПО, получена градуировочная зависимость 

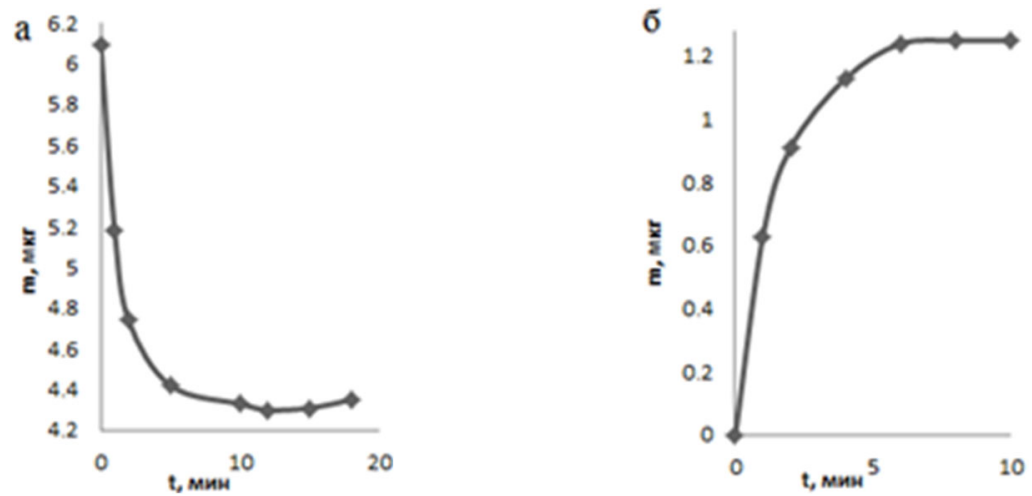

Рис. 5. Зависимость изменения массы полимерной пленки от продолжительности извлечения молекул тетрациклина регенерирующим раствором (1) - (a) и изменения массы сорбированного тетрациклина от времени встраивания (б)

Fig. 5. Dependence of the change in the weight of the polymer film on the durationof the extraction of tetracycline molecules by the regenerating solution (1) - (a) the change in the weight of the sorbed tetracycline on the time of incorporation (b).

Таблица 2. Характеристик распознающего слоя пьезоэлектрического сенсора $(\mathrm{P}=0.95, \mathrm{n}=3)$ Table 2. Characteristics of the recognition layer of a piezoelectric sensor $(\mathrm{P}=0.95, \mathrm{n}=3)$

\begin{tabular}{|c|c|}
\hline Параметр & Величина \\
\hline МПмо, мкг $_{\text {пемпата }}$ мкг & $6.1 \pm 1.1$ \\
\hline $\mathrm{m}_{\text {те }}$, мкг & $1.2 \pm 0.5$ \\
\hline$\Delta \mathrm{m}_{\mathrm{BC}}$, мкг & $0.6 \pm 0.3$ \\
\hline $\mathrm{R}_{\text {, ммоль } / \mathrm{cm}^{2}}$ & $0.6 \pm 0.2$ \\
\hline $\mathrm{R}_{1}$, ммоль $/ \mathrm{cm}^{2}$ & $0.029 \pm 0.011$ \\
\hline $\mathrm{R}_{2}$, ммоль $/ \mathrm{cm}^{2}$ & $0.014 \pm 0.006$ \\
\hline
\end{tabular}

Таблица 3. Метрологические характеристики распознающего слоя пьезоэлектрического сенсора на основе $\mathrm{Fe}_{3} \mathrm{O}_{4} @$ @МО для определения тетрациклина $(\mathrm{P}=0.95 ; \mathrm{n}=3)$

Table 3. Metrological characteristics of the recognition layer of a piezoelectric sensor based on $\mathrm{Fe}_{3} \mathrm{O}_{4} @ \mathrm{MIP}$ for the determination of tetracycline $(\mathrm{P}=0.95 ; \mathrm{n}=3)$

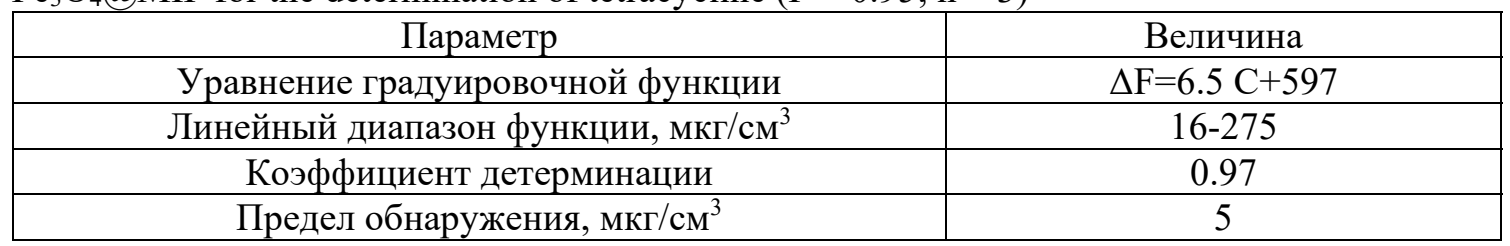

аналитического сигнала от концентрации, рассчитан предел обнаружения (табл.3). Установлено, что продолжительность формирования распознающего слоя сенсора на основе $\mathrm{Fe}_{3} \mathrm{O}_{4} @ \Pi \mathrm{MO}$, позволяет сократить продолжительность иммобилизации до 70 мин, что в 25 раз меньше, чем при формировании покрытия для иммуносенсора [29]. Характеристики пьезоэлектрического сенсора на базе магнитных частиц $\mathrm{Fe}_{3} \mathrm{O}_{4} @$ @МО свидетельствуют о возможности его применения для выявления и определения тетрациклина в жидких средах.

\section{Заключение}

Описана процедура синтеза магнитных частиц $\mathrm{Fe}_{3} \mathrm{O}_{4} @$ ПМО с молекулярными отпечатками тетрациклина методом «ядро-оболочка». Методами турбидиметрии и АСМ оценены размеры магнитных наночастиц. Показано, что применение частиц $\mathrm{Fe}_{3} \mathrm{O}_{4} @$ ПМО в распознающем слое пьезоэлектрического сенсора позволяет упростить процесс его формирования и проводить определение тетрациклина в жидких средах в интервале $16-275$ мкг/ $\mathrm{cm}^{3}$. 
Исследование выполнено при финансовой поддержке РФФИ

и Липецкой области в рамках научного проекта № 20-43-480001.

The research was funded by RFBR and Lipetsk Region, project number 20-43-480001.

\section{Список литературы}

1. Gupta N., Pant P., Gupta C., Goel P., Jain A. et al. // Materials Research Innovations. 2018. Vol. 22. pp. 434-450.

2. Ahmadi M., Elmongy H., Madrakian T., Abdel-Rehim M. // Analytica Chimica Acta. 2017. Vol. 959. pp. 1-21.

3. Губин С.П., Кокшаров Ю.А., Хомутов Г.Б., Юрков Г.Ю. // Успехи химии. 2005. Т. 74. С. 539-574.

4. Толмачева В.В., Апяри В.В., Кочук Е.В., Дмитриенко С.Г. // Журн. аналит. химии. 2016. Т. 71. No 4. С. 339-356.

5. Chahkandi M., Amiri A., Roghayyeh S., Arami S. // Microchem. Journal. 2019. Vol. 144. pp. 261-269.

6. Ma W.-F., Zhang Y., Li L.-L., You L.-J. et al. // ACS Nano. 2012. Vol. 6. pp. 3179-3188.

7. Ma W.-F., Zhang C., Zhang Y.-T., Yu M. et al. // Langmuir. 2014. Vol. 30. pp. 6602-6611.

8. Janoš P., Kormunda M., Životský O., Pilařová V. // Sep. Sci. Technol. 2013. Vol. 48. pp. 2028-2035.

9. Tahmasebi E., Yamini Y., Mehdinia A., Rouhi F. // J. Sep. Sci. 2012. Vol. 35. pp. 22562265.

10. Shahrebabak S.M., Saber-Tehrani M., Faraji M., Shabanian M., Aberoomand-Azar P. // Environ Monit Assess. 2020. Vol. 192. pp. 262272.

11. Samadishadlou M., Farshbaf M., Annabi N., Kavetskyy T. et al. // Artificial Cells, Nanomedicine and Biotechnology. 2018. Vol. 46. No 7. pp. 1314-1330.

12. Korneva G., Ye H., Gogotsi Y. // Nano Letters. 2005. Vol. 5. pp. 879-884.

13. Гражулене С.С., Золотарева Н.И., Редькин А.Н., Шилкина Н.Н. и др.// Ж. прикл. химии. 2018. Т. 91. № 11. С.1642-1649.
14. Oh J.K., Park J.M. // Prog. Polym. Sci. 2011. Vol. 36. pp. 168-189.

15. Yang C., Wu J., Hou Y. // Chem. Commun. 2011. Vol. 47. pp. 5130-5141.

16. Кубракова И.В., Кощеева И.Я., Пряжников Д.В., Мартынов Л.Ю. и др. // Журн. аналит. химии. 2014. Т. 69. o 4. С. 378-389.

17. Liu T., Xie J., Zhao J., Song G., Hu Y. // Food Anal. Methods. 2014. Vol. 7. pp. 814-819.

18. Yan H., Cheng X., N. Sun // Journal of Agricultural and Food Chemistry. 2013. Vol. 61. pp. 2896-2901.

19. Changa L., Chena S., Li X. // Applied Surface Science. 2012. Vol. 258. pp. 6660-6664.

20. Chen L., Li B. // Food Chem. 2013. Vol. 141. pp. 23-28.

21. Kong X., Gao R., He X., Chen L. et al. // J. Chromatogr. A. 2012. Vol. 1245. pp. 8-16.

22. Turiel E., Díaz-Álvarez M., MartínEsteban A. // Separation Science. 2020. Vol. 43. Is. 16. pp. 3304-3314.

23. Rocha-Santos T.A.P. // Trend. Anal. Chem. 2014. Vol. 62. pp. 28-36.

24. Ермолаева Т.Н., Фарафонова О.В., Бессонов О.И. // Сорбичонные и хроматографические проиессы. 2019. Т. 19. № 6. С. 682-690.

25. Ермолаева Т.Н., Фарафонова О.В., Чернышова В.Н., Зяблов А.Н. и др. // Журн. аналит. химии. 2020. Т. 75. № 10. С. 898-906.

26. Karaseva N, Ermolaeva T, Mizaikoff B // Sensors and actuators B: Chemical. 2018. Vol. 225. pp. 199-208.

27. Sauerbrey G.Z. // Phys. Chem. 1959 Vol. 155. pp. 206-222.

28. Chen H., Zhang Y., Gao B., Xu Y. et al. // Environ. Sci. Pollut. Res. 2013. Vol. 20. pp. 8567-8578.

29. Ермолаева Т.Н., Фарафонова О.В. Патент на изобретение RU $2687742 \mathrm{C} 1$. 16.05.2019. Заявка № 2017147140 от 29.12.2017. 


\title{
Synthesis and application of magnetic molecularly imprinted with tetracycline polymer nanoparticles in a piezoelectric sensor
}

\author{
(C) 2021 Bizina E.V., Farafonova O.V., Tarasova N.V., Ermolaeva T.N. \\ Lipetsk State Technical University, Lipetsk, Russian Federation
}

\begin{abstract}
The aim of the study was the synthesis of magnetic molecularly imprinted with tetracycline polymer nanoparticles $\left(\mathrm{Fe}_{3} \mathrm{O}_{4} @\right.$ MIP) by the core-shell by grafting method and assessing the possibility of their application as recognition components of a piezoelectric sensor.

In the course of the study, the conditions for the synthesis of magnetic polymers with molecular imprints of tetracycline by the "core-shell" method were established. Molecular imprinted polymers (MIP) synthesized by the core-shell method have already proven themselves as selective sorbents for the concentration and separation of various organic compounds. In this case, firstly, the spherical shape of the core is achieved and the degree of dispersion of the synthesized particles $\mathrm{Fe}_{3} \mathrm{O}_{4} @ \mathrm{MIP}$ with a uniform surface morphology increases, and secondly, molecular imprints are concentrated in a rather thin layer, which speeds up re-binding to the template. Magnetic cores were obtained by a modified coprecipitation method, then their surface was hydrophobized with oleic acid to facilitate fixation of the polymer layer, and then a molecularly imprinted polymer "shell" was synthesized by free radical polymerization using methacrylic acid and ethylene glycol dimethocrylate.

By studying the turbidity spectrum, the average radii of magnetic nuclei $\mathrm{Fe}_{3} \mathrm{O}_{4}(65 \pm 3 \mathrm{~nm})$, magnetic particles $\mathrm{Fe}_{3} \mathrm{O}_{4 \mathrm{r}} @$, PMO $(93 \pm 4 \mathrm{~nm})$ and $\mathrm{Fe}_{3} \mathrm{O}_{4} @$ NIP $(127 \pm 6 \mathrm{~nm})$ and the estimated thickness of the surface polymer layer for $\mathrm{Fe}_{3} \mathrm{O}_{4} @$ MIP $(28 \pm 5 \mathrm{~nm})$ and $\mathrm{Fe}_{3} \mathrm{O}_{4} @ \mathrm{NIP}(62 \pm 8 \mathrm{~nm})$. The results obtained correlated with the sizes of nanoparticles determined by the AFM method. The conditions for the formation of a recognition layer based on $\mathrm{Fe}_{3} \mathrm{O}_{4} @$ MIP particles on the surface of a gold electrode of a piezoelectric sensor under the influence of a magnetic field generated by a neodymium magnet were studied. The method of piezoelectric microweighting was used for the estimation of the surface concentration of molecular imprints and the stability of the recognition layer based on magnetic $\mathrm{Fe}_{3} \mathrm{O}_{4} @$ MIP tetracycline particles. The metrological characteristics of a piezoelectric sensor for the determination of tetracycline have been established: the equation of the calibration function has been obtained, the range of the determined antibiotic contents has been determined (16$275 \mu \mathrm{g} / \mathrm{ml})$, and the detection limit has been calculated $(4.5 \mu \mathrm{g} / \mathrm{ml})$. Parameters of a piezoelectric sensor based on magnetic $\mathrm{Fe}_{3} \mathrm{O}_{4} @$ MIP particles indicate the possibility of its use for the detection and determination of tetracycline in liquid media.
\end{abstract}

Keywords: tetracycline, polymers with molecular imprints, core-shell method, surface imprinting, recognition layer of piezoelectric sensor.

\section{References}

1. Gupta N., Pant P., Gupta C., Goel P., Jain A. et al., Materials Research Innovations, 201, Vol. 22, pp. 434-450.

2. Ahmadi M., Elmongy H., Madrakian T., Abdel-Rehim M., Analytica Chimica Acta, 2017, Vol. 959, pp. 1-21.

3. Gubin S.P., Koksharov YU.A., KHomutov G.B., YUrkov G.Yu., Uspekhi khimii, 2005, Vol. 74, pp. 539-574.

4. Tolmacheva V.V., Apyari V.V., Kochuk E.V., Dmitrienko S.G., Zhurn. analit. Khimii, 2016, Vol. 71, No 4, pp. 339-356.

5. Chahkandi M., Amiri A., Roghayyeh S., Arami S., Microchem. Journal, 2019, Vol. 144, pp. 261-269.

6. Ma W.-F., Zhang Y., Li L.-L., You L.-J. et al., ACS Nano, 2012, Vol. 6, pp. 3179-3188.
7. Ma W.-F., Zhang C., Zhang Y.-T., Yu M. et al., Langmuir, 2014, Vol. 30, pp. 6602-6611.

8. Janoš P., Kormunda M., Životský O., Pilařová V., Sep. Sci. Technol., 2013, Vol. 48, pp. 2028-2035.

9. Tahmasebi E., Yamini Y., Mehdinia A., Rouhi F., J. Sep. Sci., 2012, Vol. 35, pp. 22562265.

10. Shahrebabak S.M., Saber-Tehrani M., Faraji M., Shabanian M., Aberoomand-Azar P., Environ Monit Assess, 2020, Vol. 192, pp. 262272.

11. Samadishadlou M., Farshbaf M., Anna-bi N., Kavetskyy T. et al., Artificial Cells, Nanomedicine and Biotechnology, 2018, Vol. 46, No 7, pp. 1314-1330.

12. Korneva G., Ye H., Gogotsi Y., Nano Letters, 2005, Vol. 5, pp. 879-884. 
13. Grazhulene S.S., Zolotareva N.I., Red'kin A.N., SHilkina N.N. et al., Zh. prikl. Khimii, 2018, Vol. 91, No 11, pp. 1642-1649.

14. Oh J.K., Park J.M., Prog. Polym. Sci., 2011, Vol. 36, pp. 168-189.

15. Yang C., Wu J., Hou Y., Chem. Commun., 2011, Vol. 47, pp. 5130-5141.

16. Kubrakova I.V., Koshcheeva I.Ya., Pryazhnikov D.V., Martynov L.YU. et al., ZHurn. analit. Khimii, 2014, Vol. 69, No 4, pp. 378-389.

17. Liu T., Xie J., Zhao J., Song G., Hu Y., Food Anal. Methods, 2014, Vol. 7, pp. 814-819.

18. Yan H., Cheng X., Sun N., Journal of Agricultural and Food Chemistry, 2013, Vol. 61, pp. 2896-2901.

19. Changa L., Chena S., Li X., Applied Surface Science, 2012, Vol. 258, pp. 6660-6664.

20. Chen L., Li B., Food Chem., 2013,. Vol. 141. pp. 23-28.

21. Kong X., Gao R., He X., Chen L. et al., $J$. Chromatogr. A, 2012, Vol. 1245, pp. 8-16.

Бизина Екатерина Вячеславовна - аспирант кафедры химии, Липецкий государственный технический университет, Липецк

Фарафонова Ольга Вячеславовна - к.х.н., доцент кафедры химии, Липецкий государственный технический университет, Липецк.

Тарасова Наталья Владимировна - к.т.н., доцент кафедры нанотехнологии, Липецкий государственный технический университет, Липецк.

Ермолаева Татьяна Николаевна - д.х.н., профессор кафедры химии, Липецкий государственный технический университет, Липецк.
22. Turiel E., Díaz-Álvarez M., MartínEsteban A., Separation Science, 2020, Vol. 43, Is. 16 , pp. 3304-3314.

23. Rocha-Santos T.A.P., Trend. Anal. Chem., 2014, Vol. 62, pp. 28-36.

24. Ermolaeva T.N., Farafonova O.V., Bessonov O.I., Sorbtsionnye i khromatograficheskie protsessy, 2019, Vol. 19, No 6, pp. 682-690.

25. Ermolaeva T.N., Farafonova O.V., CHernyshova V.N., Zyablov A.N. et al., ZHurn. analit. Khimii, 2020, Vol. 75, No 10, pp. 898906.

26. Karaseva N, Ermolaeva T, Mizaikoff B., Sensors and actuators B: Chemical, 2018, Vol. 225, pp. 199-208.

27. Sauerbrey G.Z., Phys. Chem., 1959, Vol. 155, pp. 206-222.

28. Chen H., Zhang Y., Gao B., Xu Y. et al., Environ. Sci. Pollut. Res., 2013, Vol. 20, pp. 8567-8578.

29. Ermolaeva T.N., Farafonova O.V. Patent na izobretenie RU 2687742 C1. 16.05.2019. Zayavka № 2017147140 ot 29.12.2017.

Bizina Ekaterina V. - post-graduate, Department of Chemistry, Lipetsk State Technical University, Lipetsk

Farafonova Olga V. - associate prof., Ph.D. (chemistry), Department of Chemistry, Lipetsk State Technical University, Lipetsk, e-mail: farafonova.ov@mail.ru.

Tarasova Natalya V. - associate prof., Ph.D. (technical sciences) Department of Nanotechnology, Lipetsk State Technical University, Lipetsk.

Ermolaeva Tatyana N. - prof., grand Ph.D (chemistry), Department of Chemistry, Lipetsk State Technical University, Lipetsk, e-mail: etn@stu.lipetsk.ru. 